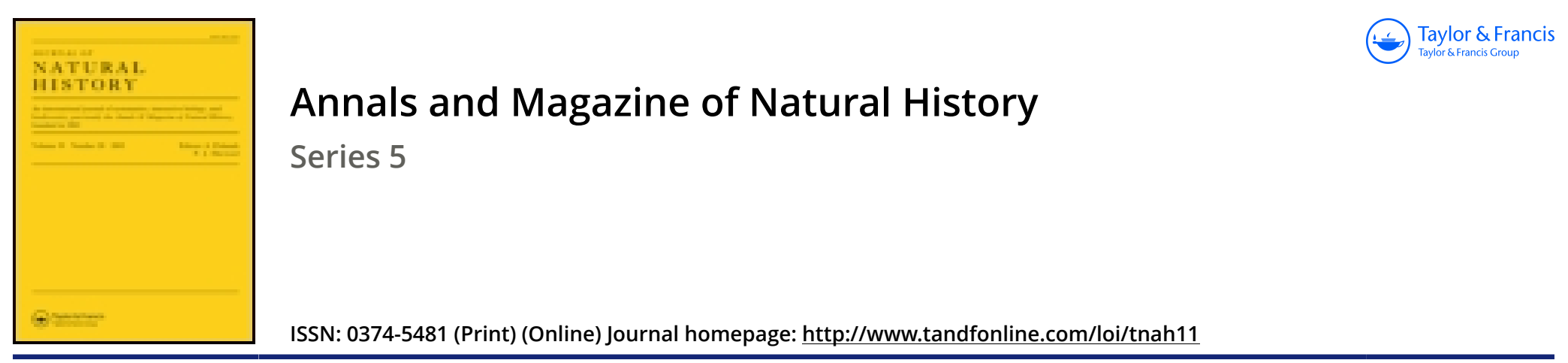

\title{
XLIV.-Notes on the internal and external structure of Palœozoic Crinoids
}

\section{Charles Wachsmuth}

To cite this article: Charles Wachsmuth (1878) XLIV.-Notes on the internal and external structure of Palœozoic Crinoids, Annals and Magazine of Natural History, 1:5, 379-392, DOI: $10.1080 / 00222937808682349$

To link to this article: http://dx.doi.org/10.1080/00222937808682349

$$
\text { 册 Published online: } 15 \text { Oct } 2009 .
$$

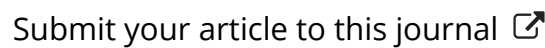

Џ Article views: 5 
ever, seems to point out that Purisiphonia did not belong to the Euplectellidoe, nor to the hexactinellids with scopuliform spicules, as in all these, so far as my observation extends, the rays of the rosette are arranged en fleur-de-lis.

Lastly, we learn from Mr. Moore's paper that specimens of this sponge are not uncommon in the calcareous boulders which are found in the "brittle marl" of the Creek of Wollumbilla, and among the "grits and sandstones" of the neighbouring plains, indicating, from the other fossils which they contain, and their worn state, that such boulders belong to a drift deposit, and originally came from Upper-Oolitic and Cretaceous strata, which have previously existed in Australia in their entirety, if this be not the case now, in some parts as yet undiscovered.

\section{XLIV.-Notes on the Internal and External Structure of Palcozoic Crinoids. By Charles Wachsmuth*.}

THE structure of fossil Crinoids has occupied the attention of many able writers; and numerous ingenious and plausible theories have been advanced to demonstrate the physiological functions of the various parts of their complicated organization. The results of investigations heretofore made have been by no means harmonious; and newly discovered evidence renders many of these theories wholly unsatisfactory. I have been favoured with unusual facilities for obtaining accurate knowledge upon many of the questions involved in these researches, and therefore hope that I may contribute useful information on the subject. The collections of eighteen years at Burlington, Iowa, have brought to light material, unrivalled elsewhere, for this study. I have obtained upwards of four hundred species of Crinoids at that locality, many of the specimens in such a condition that not only the whole calcareous skeleton of the animal, but even the most delicate internal organs *are preserved almost as perfectly as in those dredged from our present seas. Careful observations, extending through many years, and study of this material in connexion with extensive collections from other formations, have enabled me to add to the present knowledge of these forms many interesting and important facts, and have led me to conclusions which I present in the following pages.

\section{The Mouth and the Tubular Skeleton below the Vault.}

The apparent absence of a mouth has proved to be one of

* From 'Silliman's American Journal,' August 1877. 
the most perplexing points in the investigation of the structure of Palæozoic Crinoids. In all Radiates (even of the most inferior groups) this organ is located invariably at one end of the vertical axis, although that axis or centre is not always. the centre of figure. It occupies in the recent Crinoids the upper end of this axis; but in many at least of the Palæozoic Crinoids, the portion of the summit where, from analogy, we should expect to find the oral aperture is perfectly covered by solid and immovable plates. The only aperture in connexion with the visceral cavity is lateral or subcentral, placed outside of the radiation and within the interradial area, where, from analogy, we must expect to find the anus. If, as Mr. Billings *, Dr. Whitet, and the older writers on Crinoids supposed, this aperture served both as mouth and vent, so that these Crinoids took in their food through the anus, this stands as the sole exception to the rule governing the class. It is true the Ophiurans, for instance, have no separate anal opening, and the same aperture performs both oral and anal functions ; but it is placed within the radial centre, and therefore cannot be homologized with the interradial orifice of Palæozoic Crinoids. In Antedon rosaceus, although the nascent Crinoid develops already within the pseudembryo a separate mouth and vent, a single orifice serves for some time both as oral and anal aperture; yet it is the permanent mouth, occupying the centre of the ambulacral system $\ddagger$. While we thus find the mouth performing permanently or temporarily anal functions, we have on the other hand no evidence, either from recent nature or from embryology, that an anus ever becomes developed into, or performs the office of, a mouth.

The Crinoids of our present seas live exclusively on microscopic food; and we must expect to find that the Palæozoic Crinoids subsisted upon very similar food and had a very similar mode of alimentation. Whenever in Antedon alimentary particles fall upon the furrows of the arms or pinnulæ, they are transmitted downward along these furrows to the mouth wherein the furrows terminate. Dr. Carpenter remarks on this subject $\S:-$

"The transmission of alimentary particles along the ambulacral furrows is the result of the action of cilia with which their surface is clothed. Although I have not myself suc-

* Silliman's Journ. 1869, vol. xlviii. no. 142, p. 69.

+ Journ. Nat. Hist. Boston, 1862, vol. vii. no. 4. p. 481.

$\ddagger$ Sir Wyville Thomson, Phil. Trans. of the Royal Society.

$\S$ "Researches on the Structure, Physiology, and Development of Antedon rosaceus.-Part I.", by W. B. Carpenter, M.D., F.R.S. (Phil. Trans. Roy. Soc. vol. clvi. part 2, 1866). 
ceeded in distinguishing cilia on the surface which forms the floor of these furrows, yet I have distinctly seen such a rapid passage of minute particles along their groove as I could not account for in any other mode, and I am therefore disposed to believe in their existence. Such a powerful indraught, moreover, must be produced, about the regions of the mouth, by the action of the large cilia which fringe various parts of the internal wall of the alimentary canal, as would materially aid in the transmission of minute particles along those portions of the ambulacral furrows which immediately lead toward it; and it is, I feel satisfied, by the conjoint agency of these two moving powers that the alimentation of Antedon is ordinarily effected."

It appears from these observations that the mouth of Antedon has no special functions as such, but is merely a receiving centre or general passage, into which the food which accidentally falls into contact with the furrows of the arms or pinnula enters-a passage which might as well be external, hidden beneath a vault, as open to the surrounding element, provided the food could be brought into contact with it. 'The large cilia on the inner wall of the alimentary canal, which Dr. Carpenter describes as being capable of producing such a powerful indraught to the region of the mouth, afford, it seems to me, also a very satisfactory explanation of the mode by which the transmission of food was effected in Palæozoic Crinoids. How much more powerful must have been the effects of these cilia in individuals in which mouth and furrow were arched over and in which the current was unobstructed from without! Considering, further, that probably the covered parts of the food-channels themselves were fringed with cilia of similar functions, it could have been of but little moment how remote from the mouth the food entered. We find another most striking example in confirmation of this supposition in Hypomene Sarsi, Lovén, a recent Cystidean, indicating, in analogy with recent nature, that Crinoids had the mouth sometimes internal. Prof. Lovén found in the covered parts of its channels microscopic Crustacea, larval bivalves, and other remains of the food of the animal, apparently taken through the open parts of the channels. Applying this observation to Palæozoic Crinoids, it seems very probable that their food was taken up along the open parts of the arms or pinnula, and conveyed through the closed parts to the concealed mouth.

Dr. Ludwig Schultze, in his excellent 'Monograph on the Echinoderms of the Eifel' (Vienna, 1867), was, so far as I know, the first author who suggested the idea that all Crinoids which are covered on their ventral side by solid plates, and have but one orifice, were provided with an internal 
mouth. He further suggested that the food was conveyed by the open food-groove to the inner cavity through the armopenings at the base of the arms, by means of subtegminal channels along the inner surface of the vault.

Dr. Lütken, fully confirming Dr. Schultze's observations, gives a full description of the ducts and subtegminal galleries, and compares these with the covered food-grooves in Hypomene Sarsi, expressing the opinion that the galleries underneath the summit, which he considered to be closed at the bottom and thus transformed into ducts, were food-passages.

Meek and Worthen describe and figure, in the Illinois Geological Report, vol. v., from my former collection, now in the Museum of Comparative Zoology at Cambridge, several specimens of well-preserved digestive organs, and also an Actinocrinus proboscidialis, in which a skeleton of tubular canals proceeds from a point below the central axis of the vault to the arms. There are in that specimen five main tubes which bifurcate midway toward the arm-bases, each division bifurcating: again, sending a branch to each one of the twenty arms of that species. The main tubes and branches are constructed on their lower side of alternating plates, upon which, on either side, a second row of minute quadrangular interlocking plates is attached, longitudinally arranged, thus covering the tubes. The upper rows of plates are not preserved in this specimen; but I have found them in two specimens of Strotocrinus, which I obtained recently, in which they are well preserved and in place. The condition of the specimen, as Meek and Worthen remark, leaves but little doubt that the tubes form through the arm-openings of the calyx a continuation of the arm-furrows. In removing parts of the vault, I unfortunately broke the upper part of the fragile skeleton; but enough is preserved to prove that the five main tubes did not connect: directly with each other, but communicated at their upper end (separately, as it seems) with an annular vessel of which traces are yet preserved. Such a vessel was found in wonderful preservation in a specimen of Actinocrinus Verneuitianus, Shum. The radiating canals were here not preserved; but the little openings through which they communicated are plainly visible in the circular organ. There are, at the lower side of the ring, which is composed of minute interlocking plates, five other small openings, which, alternating with the former ones, were apparently in connexion with organs of the interradial system (communicating perhaps with a circulatory system). The whole upper part of the stomach is here placed within the ring-differing in this particular from Actinocrinus proboscidialis, in which only a spiral alimentary tube passes out from 
the interior of the convoluted digestive organ. The several tubes of the skeleton, though closely following the direction of the vault, but without touching it, are placed here within some obscure furrows along its inner surface.

Such furrows in the vault can be observed in many Palæozoic Crinoids. They are either elevations of the vault itself or are formed by ridges or partitions on the inner surface, which are always deepest toward the anal side. The grooves are sometimes closed underneath, particularly in very old specimens, thus forming regular ducts or tunnels. Their arrangement seems to be similar in all these Crinoids, no matter whether the species has a subcentral proboscis or merely a lateral opening; they always diverge from a plane on the inner wall of the vault, in front of the anus, and branch to the armopenings.

For further information on this subject, I will now call attention to some most excellent natural casts, mostly of Actinocrinidæ, which I obtained from cherty layers of the Upper Burlington Limestone. The outer shell or limestone test was generally attached when I found them, but so much decayed that it was removed by the least touch. The substance of which the casts are formed appears to have been a fine siliceous mud which could penetrate the smallest pores. The internal organs are of course not preserved; but their impressions at the surface of the casts throw much light on the structure beneath the vault. The centre of radiation appears here a small pentagonal, rounded, or, in species with strong: subcentral proboscis, subtriangular or even heart-shaped space or plane, enclosed by a deep groove, from which, in some of these specimens, elevated ridges, alternating with depressions, pass out toward the arms; but before quite reaching them, there proceeds, from below the ridges of the casts, to every arm a smaller ridge which clearly indicates the tubular canal, as described in Actinocrinus proboscidialis. The casts are so perfect that I can even detect at some places the impressions of the alternating minute plates of the tubes.

The casts are easily understood, if we remember that the broader ridges are impressions of the grooves in the vault, and that the depressions correspond to the partitions which formed the grooves. The radiating tubes, where they do not appear in the casts, were evidently placed at some distance from the vault, and therefore enveloped and obliterated by the material forming the casts; but on approaching the arm-bases they closely underlie the test and their counterparts are preserved.

I have already mentioned in the casts a pentagonal space, 
surrounded by a furrow, as being the centre of radiation. It is located anterior to the proboscis, occupying a central or nearly central position. The middle of the space is occupied frequently either by a small opening or by a little cone indicating an aperture leading toward the inner cavity; but in these casts the aperture is isolated, and there appears on the surface no connexion with the annular groove surrounding it. To understand this structure it becomes necessary to examine first some other casts from the same locality, mostly of Strotocrinus and Actinocrinus, but also several of Batocrinus, though of different species from those which I have just described. These casts have no annular groove; and the radiation, which is marked by elevated rounded ridges, almost like strings overlying the surface, proceeds from a point in the centre where $I$ noticed the little aperture in the former casts. The strings diverge toward the arm-bases in the same manner as the tubular canals; they are stronger toward the centre, decreasing in size with each bifurcation. That these ridges are remains of muscular cords is not probable, from the perishable nature of such organs; and they are not their casts, or they should have left depressions in place of elevations. They can only be casts of passages which communicated with the central aperture, and which were evidently yet preserved when the siliceous mud, forming the casts, penetrated the body; but their calcareous parts becorning in the course of time decomposed, a cast was left only of their inner channel; and this explains their string-like appearance. The little central aperture, located at the upper end of the vertical axis, occupied on the casts, and hence below the vault of these Crinoids, exactly the same position that the internal mouth of Antedon occupies at the peristome; while the position of the string-like ridges (in case they represent passages, as I can hardly doubt) is analogous to that of the open food-grooves of recent Crinoids.

The annular groove on the casts is probably an impression of the annular vessel, of which the calcareous parts have decomposed. This organ, in the fossil state, heretofore only observed in the case of Actinocrinus Verneuilianus, existed undoubtedly in all Crinoids. That we find no trace of it in some of the casts is no proof to the contrary; it may have been sometimes composed of more perishable material and therefore not preserved, or situated at a greater distance from the vault and covered by the substance of which the casts were formed.

\section{The Ventral Furrow of the Arms.}

The arms of Palæozoic Crinoids manifest great diversity in outer form and structure, but are invariably provided with a 
ventral furrow, which continues from the arm-bases up to the tips of the arms and along the pinnulæ. The pinnulæ spring out alternately right and left from the arm-plates, their furrows connecting with that of the arm and forming, in fact, a continuation of the same.

The furrow appears, in specimens in ordinary preservation, as a simple groove, which communicates through the armopenings with the inner cavity of the body. Only in rare instances has the furrow been found covered by minute plates, whose construction, however, has heretofore not been ascertained. The best specimen of this kind that $I$ have seen is a Cyathocrinus malvaceus, in which the little plates above the furrow can be studied in all their details with the greatest precision. The specimen is the property of Frank Springer, Esq., who had the kindness to leave it with me for investigation and description. The arms of Cyathocrinus are composed of long slender joints with a wide ventral furrow. They bifurcate frequently, each branch bifurcating at intervals again. There appears on the arms of Cyathocrinus no scar for the attachment of pinnulæ; and as these appendages have never been observed in the genus, it is probable that the many little branches performed their functions. In Mr. Springer's specimen the plates above the furrow consist of two rows of minute pieces on either side, the inner rows of which join in the middle, interlock with each other, and form an apparently solid covering. The outer plates which are attached to the arm-joints are toward the upper end of the arms placed partly upon the edges of the joint, but nearer the calyx rest wholly against the edges of the upper part of the ventral furrow. They are longitudinally arranged, partly hidden from view by the inner plates. The visible part is quadrangular, with a narrow tooth-like projection toward the lower end of each plate, which is directed inward and slightly downward as a sharp, elongated process, and forms a support for the inner plates. The inner plates are elongated triangular, resting with their shorter sides against the inner faces of the outer series, and, between the tooth-like extensions, overlapping them with their bevelled lateral edges, in such a manner that each plate exteriorly fits in and fills the space between each pair of similar triangular plates on the other side. The two longer sides interlock with corresponding sides of similar plates of the opposite row, their sharp angles or apices meeting the sutures between the opposite quadrangular plates. At each of these points of junction, just beyond the apex of each triangular piece, on either side of the furrow, there is a little pore, which evidently communicates with the inner channel. There are Ann. \& Mag. N. Hist. Ser. 5. Vol. i. 
six sets of plates to each arm-joint, all the plates being imbricated from the lower side upward (that is, the lower ones overlap slightly the edges of the upper ones), thus facilitating the movements of the arms.

In describing the skeleton below the vault, I suggested that the tubes were a continuation of the arm-furrows. A transverse section of the arm, examined with the aid of a good magnifier, shows that the tubes themselves were, at least in this species, continued along the arms to their tips and rested within the arm-furrow, with their sides closely attached to the upper edges of the arm-joint. The tubes do not touch the floor of the arm-grooves, but leave a good-sized subtriangular channel underneath. The small plates, above described, form the upper or outer wall of the tube ; and two sets of small plates enclose it below. The position of the two upper sets of quadrangular pieces is nearly erect, leaning inward, the triangular cross pieces lying horizontally, thus forming a regular tube or tunnel with a nearly round channel.

I was at first of the opinion, after examining Mr. Springer's specimen, that the arm-furrows of Palæozoic Crinoids were permanently covered by solid plates, like the ventral side of their cup; but upon comparing these arms with those of a specimen of Cyathocrinus viminalis in my own collection, I became fully convinced that the inner plates could be opened or shut at will by the animal. The arms of my specinen are spread out; their ventral furrows are open, the quadrangular pieces in place; their tooth-like extensions stand out like the teeth of a saw, and are so arranged that the indentations face the salient angles of the opposite side, thus giving to the furrow a strongly zigzag appearance.

The tooth-like processes in this species are so prominent that, from their similar form, and before I had recognized this peculiar structure in Mr. Springer's specimen also, I at first took them for the triangular cross pieces; but on closer inspection I found no sutures between the projections and the quadrangular portions of the plates; and as the place of attachment for the triangular pieces is plainly visible, there can be no doubt that these plates were not preserved in the specimen. Furthermore, as the quadrangular pieces are with slight interruptions found on all the arms of the specimens most beautifully preserved, it seems almost impossible to understand how the triangular pieces could have fallen out, if they had been fastened solidly to the adjoining plates. Supported by the tooth-like projections, and resting against the edges of the quadrangular plates, they were evidently better protected than the outer pieces; and it seems to me their destruction would 
have involved that of the entire covering. I therefore believe these plates were not firmly attached in the living animal, but merely leaned against each other as well as upon the tooth-like projections, being only attached to the inner edge of the quadrangular plates by muscular or interarticular substance, and that they were, in analogy with similar plates in recent Crinoids, movable. This seems further confirmed by the construction of the plates themselves, and especially by the manner of their attachment. The inner edges of the quadrangular plates (between the projections) being slightly convex, they rested in regular sockets, which facilitated their opening in an outward direction. In case these plates, as I can no longer doubt, could be opened or closed, it seems reasonable that they were open in my specimen when the animal died; or they otherwise would have been preserved.

The position and construction of the inner channel proves most satisfactorily, and in analogy with recent Crinoids, that it contained the food-groove which conveyed the food through the arm-openings beneath the vault to the oral aperture. The small movable plates are evidently homologous with the "Saumplatten" of Antedon; and the imbrication of these plates, as well as of the entire covering, seems to hint at the conclusion that the furrow was always closed when the arms were folded up as in Mr. Springer's specimen, but that, on the contrary, as in my specimen, the furrow was open when the arms were spread, and that in this position the animal took in its food.

In describing the covering of the furrow, I have already mentioned the presence of two rows of small pores located at the angles of the triangular pieces. There is nothing to indicate that these pores were sockets of pinnulæ; if they had been the "Saumplatten" could not have opened. From their position I infer they were passages for tentacles connecting with parts of the inner tube. If this is correct, it seems to me there must have been located within the tube a passage in connexion with the ambulacral system, since the tentacles form a part of it. This is evidently the case. In a transverse section of the arm, with the help of a magnifier, I think I have detected within the tube traces of two passages-a deep groove occupying only the median region, and on each side of it $a$ small canal underlying the pores. The condition of the specimen does not enable me to say whether the two side passages connect at the bottom or not; but in either case they undoubtedly represent the ambulacral canal, the food-groove occupying only the median and upper part of the channel.

It is to be regretted that in no instance the upper part of 
the tubular skeleton has been found in perfect preservation. There has been observed beneath the vault an annular vessel, constructed of plates similar to those of the radiating tubes, with small openings directed toward the radial sides of the specimen, with the alimentary canal passing through the inner space of the ring; but its connexion with the surrounding parts was not preserved. The position of the annular organ in the centre of radiation leaves but little doubt that it is the osophageal ring or centre of the ambulacral system. The great similarity in the construction of its plates, the presence of openings corresponding to the direction of the tubes, indicate most strongly that the tubes and the circular organ were connected, and that the ambulacral canal, which I recognized in the lower passage of the arms, communicated with the pores. But, as seen from the casts, there proceeded below the vault, from the arm-bases to the centre, another series of passages, which, passing the region of the annular vessel, united in the centre. I hold these to be a continuation of the food-grooves in the arms, which evidently, passing over the top of the circular organ, terminated within the central orifice.

The position of the oesophageal ring seems at first sight to be not quite in harmony with recent nature; this organ, which, in all Echinoderms with an external mouth, is attached to the inner side of the test, is located in Palæozoic Crinoids at a distance from the vault. However, considering that the aboral vault cannot be homologized with the oral skin of recent Crinoids, and that only the tubular skeleton corresponds to the radiating passages connecting with the peristome, the vault thus forming a mere covering, we shall find the position of the circular organ perfectly harmonious with that of all other Echinoderms.

I have mentioned already that there exists in the armgroove of Cyathocrinus, beneath the tube and at the bottom of the furrow, another canal, as large as, or larger than the channel of the tube, whose functions are unknown. It was, apparently through the bottom of the arm-openings, connected with the perivisceral cavity of the calyx, and may have served for several offices, containing perhaps also the coeliac canal.

Dr. Schultze, in his Monograph on the Echinoderms of the Eifel, p. 17, gives a most excellent description of the armfurrow in Cupressocrinus. He found two sets of plates covering the furrow like a roof, and asserts that the inner pieces could be turned back in the living animal. I had overlooked this in making out my descriptions ; but it was pleasing and highly satisfactory to me to find that we both had arrived independently at the same conclusion. The construction of the arm- 
furrow of Cupressocrinus is very similar to that of Cyathocrinus. In a section of the arm of this genus I readily distinguished, by transmitted light, the food-groove, which has a narrow and deep outline, a canal on both sides of it; and I have but little doubt that the arm-furrows were similarly constructed in all Palæozoic Crinoids.

\section{The Alimentary Canal.}

Meek and Worthen publish, in the 'Geological Report of Illinois,' vol. v., most excellent descriptions and figures of an organ which occupies the greater part of the visceral cavity of Palæozoic Crinoids; they call it, from its position, in analogy with other Echinoderms, "the digestive organ." It is a large convoluted body, resembling in outer form and outline the shell of a Bulla, with a longer vertical axis, and open at both ends. The upper end is placed below the centre of the ventral disk, the lower one directed toward the column, dilated above, contracted below, coinciding with the inner space of the visceral cavity, to the walls of which it stands nearly parallel. In some cases it is subcylindrical and slightly truncate at both ends.

The organ is constructed of a great number of very minute pieces or bars with intervening meshes; but its delicate texture is but seldom observed, owing to the presence of incrustations of calcareous or siliceous matter, which fill up the meshes and give to the structure a rather dense appearance*.

The convolutions are directed outward from left to right, varying in number from two to four in different species. Judging from external appearance only, the convoluted walls of the organ appear as mere partitions leading to the inner chamber of a Bulla-shaped body. This, however, is not the fact. Examining the so-called walls in some transverse sections, I find them to be coiled, without touching each other at any point, and composed of two distinct partitions, placed side by side and closed at the edges, thus proving that the apparent walls are the coiled organ itself. According to this, the digestive organ consisted of a long flattened canal, rounded at the outer side, widest in the middle, tapering rapidly at both euds to a rather heavy flattened tube, the outer end ascending spirally toward the top of the visceral cavity, making two or more turns, while the inner one, winding in a spiral way around its own axis, passed upward to near the centre of the dome.

* To these incrustations, which are evidently deposits from the water, we owe, in a great measure, the preservation of these delicate organs; and as they are comparatively thicker in adult specimens, they seem to have accumulated already during the life of the Crinoids, and may have caused, in many instances, their death. 
In a specimen of Actinocrinus in which the digestive organ is apparently perfect, though showing the usual rough appearance, I succeeded in removing at one side the two upper convolutions, in such a manner that the detached parts can be replaced or lifted up for investigation. I had here an opportunity to examine the inner or, more properly, upper end of the alimentary canal (as distinguished from the outer end or terminal part). The top is unfortunately hidden below some inorganic matter; but enough can be seen to prove that it proceeded evidently from a place below the centre of the dome. 'The organ, where it comes into view, is an elongated tube, which, passing downwards, widens first gradually to near the middle of the visceral cavity, then rapidly until it acquires the width of at least two thirds of the entire length of the cavity. The upper end in descending spirally turns from right to left, but on becoming wider curves sharply in the opposite direction and the convolutions are now directed from left to right. The outer end, also tapering rapidly and forming a flattened tube, ascends the outside spirally from below all the way up to the top, and, I am inclined to suppose, proceeded to the proboscis, being probably analogous to the terminal intestine of the Echini, while the upper end communicated with the foodgroove.

Such, with slight modifications, was probably the construction of the alimentary canal of all Actinocrinida, Platycrinidae, \&c., but not that of the gentus Ollacrinus*. I found the alimentary canal partly preserved in Ollacrinus tuberculosus, Hall, in which it seems to have been composed of the same delicate network; but the organ consists here of a round canal which descends spirally, and, contracting gradually, takes at the lower portion of the visceral cavity an upward direction. The upper part of the organ is unfortunately not preserved in this specimen.

\section{The Anal Aperture and the Proboscis.}

The anus of Palæozoic Crinoids is placed always within one of the interradial series, which is generally wider than, and often constructed differently from, the others. The aperture is situated either in some part of the calyx itself, or at the top

* Figured by Cumberland without generic or specific diagnosis or specific name, London, 1826, in the Appendix to 'Reliquiæ Conservatæ.'

Synon. :-Gilbertocrinus, Phillips, 1836, Geol. Yorkshire, pt. ii. p. 207. Goniasteroidocrinas, Lyon \& Casseday, Suppl. Geol. Rep. Iowa, p. 70. Trematocrinus, Hall, 1860, Suppl. Iowa Geol. Rept. p. 70.

As Cumberland's figure is perfectly correct and easily identified as Ollacrinus (Gilbertocrinus) calcaratus, his generic name "Ollacrinus" must be retained according to the laws of nomenclature. 
of a long proboscis. It is a most remarkable fact that genera which evidently belong to the same group, even species apparently of the same genus (for instance, Strotocrinus), differ so widely in the construction of this organ-some having a long massive tube, reaching to several inches above the tips of their arms, while others are provided only with a plain lateral opening without any superstructure whatever.

I do not speak at present of the inflated or balloon-shaped proboscis of Zeacrinus, Coeliacrinus, Poteriocrinus, Heterocrinus, and similar genera, in which this part is more properly called " the ventral sac," as it evidently formed a large portion of the visceral cavity. Its great size compared with the lower cup, the presence of large numbers of small pores, and the position of the anal aperture near the bottom instead of at the summit, seems to imply that the anal apparatus occupied in the internal economy of this sac only a limited space. The inflated sac, accordingly, cannot be homologized with the slender, heavy-plated tube of Actinocrinus. We can only compare its lateral opening, which is generally placed low down near the arm-bases, with the anal aperture of species in which the anus is located in the ventral disk.

In addition to its regular functions, the proboscis of Palæozoic Crinoids may have had the office of expelling the water from the system. This suggestion looks not unreasonable, if we consider that the solid body of the majority of these Crinoids had apparently no other outlet. I found in one instance the proboscis split open longitudinally, and within its inner cavity a well-defined narrow tube, filling scarcely one fourth of the inner space. This tube may have connected with the terminal intestine which I have described above; and the office of the surrounding canal may have been to eject the deoxygenated water from the body. The fact that some Crinoids were provided with a proboscis reaching beyond the region of the arms, and others with no proboscis whatever, but simply a lateral opening, is easily explained; for if the rejected matter were emptied between the arms, it must have come constantly again into contact with the arm-currents, which is obviated by either plan. This accounts also for the fact that the proboscis of some species of Eretmocrinus is constantly turned to one side. The proboscis formed a natural support for the slender arms; for they are found in most specimens leaning: closely against it, while in Dorycrinus, which has no proboscis, the arms appear always clinging to its long, heavy spines, which are evidently not weapons of defence, as some authors have supposed, but merely a support and protection for the arms.

Dr. C. A. White describes, in the 'Boston Journ. of Nat. 
Hist.' vol. vii. no. 4 , p. 489 , several specimens in which the proboscis diverges at some distance above the ventral disk into two distinct branches. This may be, in some instances, the result of accidental development, but is more frequently due to an obstruction of the anal canal. I found a specimen of Batocrinus longirostris in which, close to the vault, the proboscis branches into two equally heavy tubes; and there appears immediately above their junction a strong inflation or kind of abscess. In another specimen a stoppage or disconnexion must have occurred within the body, for a second proboscis was formed at the ventral disk, developed here, as in every other instance, within the anal series or posterior side of the Crinoid. In one remarkable specimen a second proboscis breaks forth even at the lower end of the calyx, just above the basal plates. The pressure against these parts must have been enormous ; for it caused the destruction of an entire ray, the plates of which are bulging out, forming, together with the anal plates, and intermingled with smaller plates such as ordinarily compose the proboscis of this species, a large elongated cavity with a rather large aperture. All these instances give evidence of a pressure from within, and indicate that the outside opening of Palæozoic Crinoids was solely an ejective organ, and could not have had oral functions. I have already mentioned that the anus is separated from the radial series by deep partitions at the inner surface of the vault, thus excluding any connexion with the upper end of the digestive organ. Moreover the casts of Actinocrinus show that the course of the proboscis is directed toward the posterior side; and the development of the abnormal proboscis occurs invariably in the anal series. It is therefore hardly necessary to argue on Dr. White's supposition, that the abnormal second proboscis, wherever it occurs, might have served as buccal orifice, as such a theory is unsupported by analogy.

[To be continued.]

XLV.-Descriptions of new Species of Heterocera from Japan.-Part III. Greometrites*. By Ärthur G. Butrler, F.L.S., F.Z.S., \&c.

\section{Urapteridæ.}

\section{Urapteryx veneris, n. sp.}

White; primaries crossed by three brown stripes, which converge towards the inner margin; a discocellular litura of

* The Geometrites described in 'Illustrations of Lepidoptera Heterocera' are not included in this paper. 